\title{
Training Intentions and Skills Needs in the Private Sector Companies in Serbia
}

\author{
Kosovka Ognjenović ${ }^{1}$ \\ Institute of Economis Sciences, Belgrade, Serbia
}

\begin{abstract}
A B S T R A C T
This paper provides an analysis of the private sector companies' training intentions and an assessment of the occupational and skills needs in the Serbian labour market. A substantial part of the analysis was carried out using the Employers Survey data as well as data from other relevant sources. The main results of this analysis indicated the net employment growth. A rising demand was primarily revealed in the occupational classes encompassing services, craft and related trade workers, followed by professionals and skilled blue colour workers ranked as the second and third ones. A significant deficit was identified in the group of occupation-specific skills and wider competencies. The companies' training intentions signalled to the permanent need for the enhancement of present and future employees' skills. Some shortcomings of the available data sources are emphasized, and directions for future research are proposed.
\end{abstract}

KEY WORDS: employers survey, demand, labour market, skills needs, training intentions

\section{Introduction}

The debate about occupations and skills shortages in the transition countries arises due to belief that the new or privatized state- and socially-

\footnotetext{
${ }^{1}$ Address: Zmaj Jovina 12, 11000 Belgrade, Serbia, e-mai: kosovka.ognjenovic@ien.bg.ac.rs, tel. +381 11 2638-820
} 
owned companies require new skills that will increase the business productivity of the companies and led to the improvement of competitiveness of the countries. Some empirical studies confirmed that previous work experience was not a significant explanatory factor of workers' wages because new organizational and business concepts require different compositions of skills in the labour market. In other words, the skills were considered as a constraining factor of the private business growth implying that low- and unskilled workers were the first whose jobs were destroyed (Commander and Kollo, 2008; Brixiova, et al., 2009).

In the developed economies the practice of the improvement of the workforce skills through (vocational) training was well established. Different phases of the training provision were in place. Firstly, it was considered that the companies are obliged to provide the training (Acemoglu and Pischke, 1998). Then, with the improvement of the educational attainment of the workforce, the general opinion was that new labour market entrants should possess not only required occupations but also adequate skills (Ellis, 2003). In this respect, educational and training providers become the important partners of the companies. They helped the employers in recognizing the skills shortages and were in a position to get feedback on the use of skills in the companies. Especially, it was important for European economies to recognize what skills should be upgraded in order to improve innovation-led competitiveness (Neirotti and Paolucci, 2013). As a response to this approach, many incentives were in place.

In the Western Balkan countries identifying skills shortages and anticipation of skills needs (mostly from a short-term perspective) has been adopted as a part of good practice that existed in the developed countries (Bejaković and Mrnjavac, 2014). The reason for the shortage of adequate skills was the slow change of educational policies in response to structural unemployment as well as the lack of coordination in the implementation of educational and employment policies (Bartlett, 2013). Serbia established the Employers Survey in 2011 as a tool for the labour market skills needs identification. The information collected by this survey is used for planning some general and specific training upon the request of known employers within the framework of active labour market policies.

This paper is organized in the following sections. The next section considers data and methods used in order to response to the main research questions. The next part of the paper focuses on the analysis of skills needs and companies' training intentions. The paper ends with main conclusions. 


\section{Data and Methods}

Various methodologies for the assessment of skills needs are in use in the European and regional labour markets (Cedefop, 2015; Bartlett et al., 2016). However, all these methods employ questionnaire surveys as tools for data collection. Table 1 summarizes several methodological approaches that are recently used in Serbia and other European countries for the assessment of present and future skills needs, skills deficits, difficulties filling job vacancies and employee training needs.

The focus is on management and human resource specialists when such surveys are carried out in the companies. Sometimes surveys target employees in order to record their experiences regarding the use of skills acquired during the process of education and training, self-assessment of skills deficits or the training needs necessary to boost efficacy in response to jobs requirements. They usually provide a basis for medium-term projections of skills needs, serve to identify obsolete skills and occupations, as well as how the employers are satisfied with the skills of higher (and secondary) education graduates. All this should serve as a reliable guide to future students, education and training providers, employers and employees to getting them know what direction future labour market needs will evolve.

Serbia uses the Employers Survey established by the National Employment Service (NES) in 2011. This survey uses the answers of the representative sample of private companies with 10 and more employees to provide the NES with necessary information on short-term needs for occupations, the preferred level of education and required skills. The survey does not use any weighting scheme which can be considered as a shortcoming, but it avoids overrepresentation of micro companies because they are excluded from the sample. Similar instruments are in use in other Western Balkan countries (Bartlett, 2013).

In this paper, the NES Employers Survey data for 2014 and 2017 are analyzed. Additionally, several other data sources are used, such as the Labour Force Survey (LFS) data, as well as other data collected as part of independent researches published in the series of reports. In particular, the goal of the analysis is: 


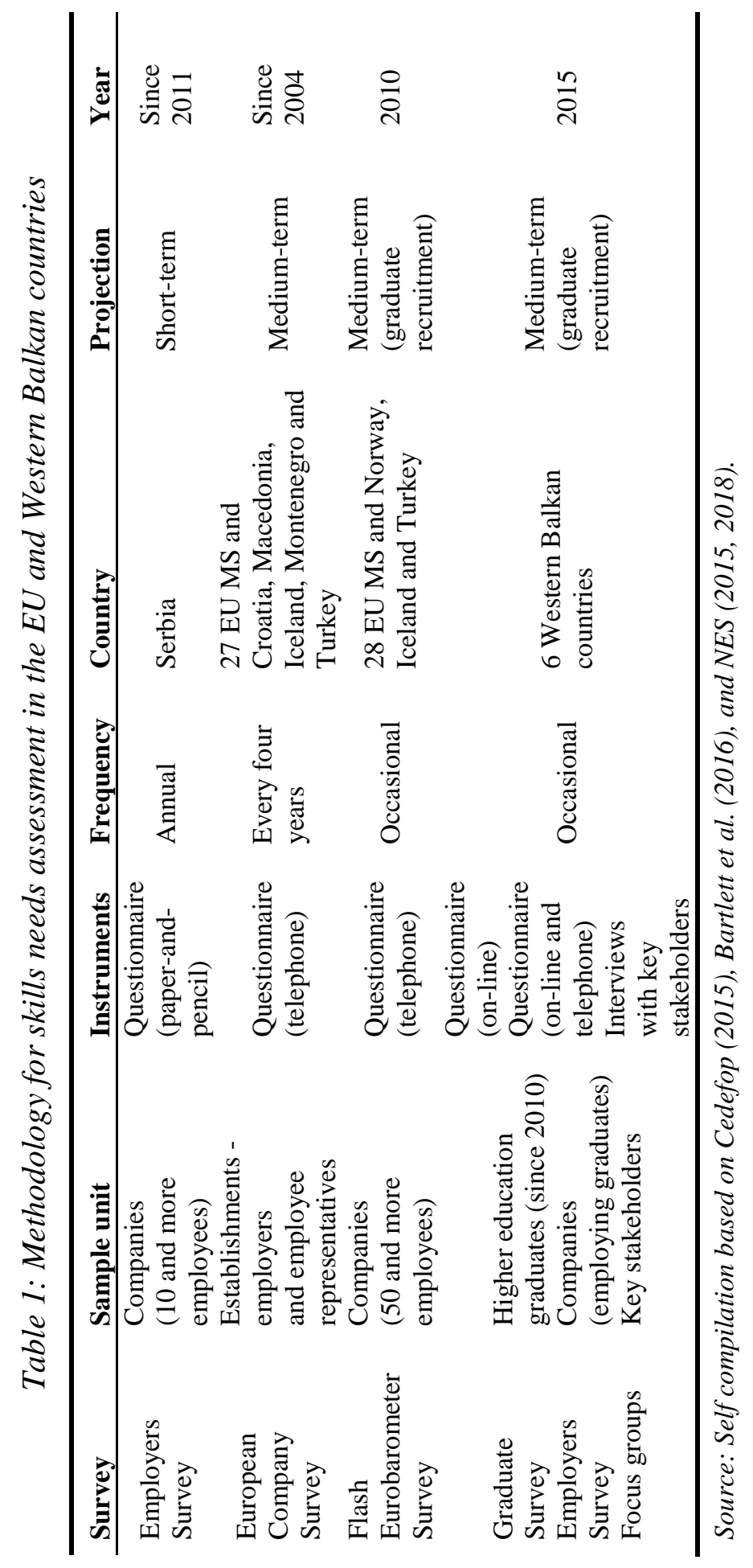


- To identify the skills the employers expect the job candidates (and present employees) should possess in order to respond to jobs requirements, and if possible reveal skills deficits;

- To determine the changes that were characteristics of the labour market supply and demand from at least two perspectives: time dynamics and regional comparisons;

- To identify the possible range of training the employers expect to provide to their employees, i.e. companies training intentions.

\section{Skill Needs Analysis and Training Intentions}

\section{Characteristics of the Workforce}

The workforce has been smoothly increasing over the 2014-2017 period (Table 2). The increase in the workforce has been more pronounced among women as depicted by the growth rate of 3.9 percentage points, while male workforce has barely increased by 1.1 percentage points. The largest increase in the active population of the age 15 years and over is recorded among higher educated individuals. Those who graduated from colleges and universities in a larger percentage entered the labour market an increase of 10.9 percentage points was recorded - while people with low educational attainment rather leave the labour market as shown by a negative rate of 2.8 percentage points. This is not unusual given the better educational structure of new entrants and the possible retirement of older workers whose education matched the previous economic system.

These trends are the result of increasing activity of the population 15 years and older. Comparing the years 2017 and 2014, the inactive population dropped by more than $6 \%$; almost the same tendencies characterized the male $(-6.3 \%)$ and female $(-6.4 \%)$ inactive population. However, when total population and, in particular, the working age population (15-64) is observed, a declining trend is notable. Serbia follows similar pattern as most of the Western Balkan countries (except Albania and Kosovo) which lose, on average, $1.4 \%$ of the working-age population (1564) per year (World Bank and WIIW, 2018). 
Table 2: Workforce, male and female employment rates in 2014 and 2017, by educational attainment $(15+)$

Panel A

\begin{tabular}{|c|c|c|c|c|c|c|c|c|}
\hline \multirow{3}{*}{ 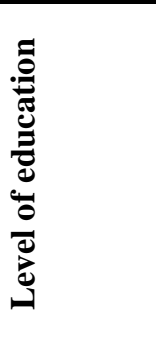 } & \multicolumn{4}{|c|}{2014} & \multicolumn{4}{|c|}{2017} \\
\hline & \multicolumn{2}{|c|}{ All } & \multicolumn{2}{|c|}{ Women } & \multicolumn{2}{|c|}{ All } & \multicolumn{2}{|c|}{ Women } \\
\hline & 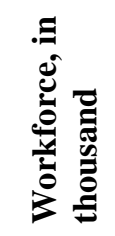 & 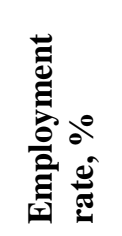 & 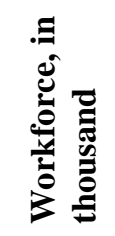 & 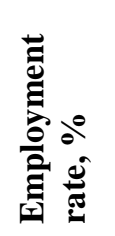 & 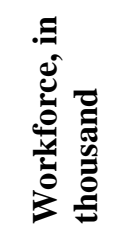 & 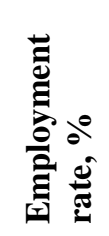 & 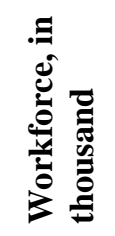 & 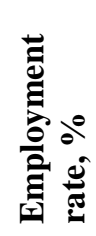 \\
\hline Low & 579.2 & 24.9 & 254.5 & 18.2 & 562.9 & 28.2 & 252.0 & 21.1 \\
\hline Medium & 1849.6 & 46.5 & 726.2 & 38.8 & 1859.2 & 51.3 & 743.2 & 43.8 \\
\hline High & 728.4 & 58.2 & 399.8 & 58.3 & 807.7 & 63.1 & 439.0 & 62.7 \\
\hline Total & 3157.2 & 41.7 & 1380.5 & 34.8 & 3229.8 & 46.7 & 1434.2 & 39.7 \\
\hline \multicolumn{9}{|l|}{ Panel B } \\
\hline \multirow{3}{*}{$\begin{array}{c}\text { Level of } \\
\text { education }\end{array}$} & \multicolumn{4}{|c|}{2014} & \multicolumn{4}{|c|}{2017} \\
\hline & \multicolumn{4}{|c|}{ Men } & \multicolumn{4}{|c|}{ Men } \\
\hline & \multicolumn{2}{|c|}{$\begin{array}{l}\text { Workforce, } \\
\text { in thousand }\end{array}$} & \multicolumn{2}{|c|}{$\begin{array}{l}\text { Employment } \\
\text { rate, \% }\end{array}$} & \multicolumn{2}{|c|}{$\begin{array}{l}\text { Workforce, } \\
\text { in thousand } \\
\end{array}$} & \multicolumn{2}{|c|}{$\begin{array}{c}\text { Employment } \\
\text { rate, \% }\end{array}$} \\
\hline Low & \multicolumn{2}{|c|}{324.7} & \multicolumn{2}{|c|}{35.0} & \multicolumn{2}{|c|}{310.9} & \multicolumn{2}{|c|}{39.0} \\
\hline Medium & \multicolumn{2}{|c|}{1123.4} & \multicolumn{2}{|c|}{53.0} & \multicolumn{2}{|c|}{1116.0} & \multicolumn{2}{|c|}{57.8} \\
\hline High & \multicolumn{2}{|c|}{328.7} & \multicolumn{2}{|c|}{58.1} & \multicolumn{2}{|c|}{368.6} & \multicolumn{2}{|c|}{63.7} \\
\hline Total & \multicolumn{2}{|c|}{1776.7} & \multicolumn{2}{|c|}{49.1} & \multicolumn{2}{|c|}{1795.5} & \multicolumn{2}{|c|}{54.2} \\
\hline
\end{tabular}

Source: SORS, Labour Force Survey for 2014 and 2017.

Note: Low=ISCED 0-2, medium=ISCED 3-4, high= ISCED 5-8.

The rising activity of the workforce has largely shifted to employment. The level of employment rose by $9.8 \%$ in 2017 compared to 2014, while the number of employed women and men increased by $11.9 \%$ and $8.3 \%$, respectively. At the same time, the number of unemployed persons dropped by $29.0 \%$ changing the labour market status - enter the employment or leave the workforce. When employment rates are observed by the educational breakdown, it can be noticed that higher employment rates are recorded for all levels of education (Table 2). However, the more pronounced shift is notable among those with higher education whose employment rate increased by 4.9 percentage points to $63.1 \%$ in 2017 . The 
employment rate was higher among high educated men by one percentage point (Table 2, Panel A), when compared with their female counterparts (Table 2, Panel B).

In the Western Balkan countries, the employment rose by $3.9 \%$ on average in 2016, which is below the respective rate for Serbia of $4.3 \%$ (population aged 15-64 years). The employment growth in Serbia was primarily led by the sectors of industry and services. LFS data for Serbia exhibited higher employment rates at all levels of education comparing to the Western Balkan countries average. Respective employment rates for those with low education in Serbia and the Western Balkan countries were $37.3 \%$ and $34.1 \%$, while for high educated individuals employment rates were $72.5 \%$ and $70.0 \%$, respectively (World Bank and WIIW, 2018). The educational structure of employees is better in Serbia than in the comparing Western Balkan countries, only the economy of Montenegro employs more high-skilled workers, in relative terms, than Serbian economy.

\section{Employment Flows and Occupational Skills Demand}

Many jobs were destroyed over the period of intensive structural reforms in Serbia. After the influence of recent economic and financial crisis, Serbian economy recovered and continued to create new jobs (Government of the Republic of Serbia, 2018a, 2018b). Comparing the years 2017 and 2014, job creation rates were almost doubled, but also the number of destroyed jobs was higher by 3.7 percentage points in 2017 than in 2014 (Table 3). The dynamics of job creation and job destruction resulted in the net employment rate of $3.0 \%$ in 2017. It should be pointed out that these estimates reflect the employers' views and that they present the private sector employers' estimates based on the actual situation in companies with ten and more employees. Given the representativeness of the private sector companies in the sample and the consecutive character of the NES Employers Survey, the indicators presented in Table 3 should provide reliable directions of employment flows in the Serbian labour market.

Table 3 provides data about job flows and net employment rates at the level of the economic sector, company size and region. The largest number of job openings was characteristic of the sector of services, but also this sector closed more jobs on average than the sectors of industry and agriculture. Rising employment rates over the observed period revealed that both the expansion and replacement demand contributed to new jobs 
creation. ${ }^{1}$ Small- and medium-sized companies show similar patterns when the proportions of jobs created and destroyed are observed, resulting in the net employment rates of 5.4\% and 4.8\% in the years 2014 and 2017, respectively. On the other hand, large-sized companies destroyed more jobs than they could have created in both years. However, the absolute value of the magnitude of the net employment rate was significantly lower in 2017 than in 2014, leaving the place for the potential growth of the employment in the sector of big employers. Belgrade's region creates more jobs than any other region in Serbia. This region also destroys many more jobs than other regions. However, the difference between created and destroyed jobs results in a strong positive net employment rate. Unlike the Vojvodina region, where the change in net employment rates between two years was the smallest, Šumadija and Western Serbia as well as Southern and Eastern Serbia regions recorded the largest positive shifts in net employment rates.

Table 3: Job creation, destruction, and net employment rates by economic sector, size and region (\%)

\begin{tabular}{lrrrrrr}
\hline & \multicolumn{3}{c}{ Job creation } & \multicolumn{2}{c}{ Job destruction } & \multicolumn{2}{c}{$\begin{array}{c}\text { Net employment } \\
\text { rate }\end{array}$} \\
& $\mathbf{2 0 1 4}$ & $\mathbf{2 0 1 7}$ & $\mathbf{2 0 1 4}$ & $\mathbf{2 0 1 7}$ & $\mathbf{2 0 1 4}$ & $\mathbf{2 0 1 7}$ \\
\hline Economic sector & & & & & & \\
Agriculture & 7.4 & 13.7 & 10.9 & 10.2 & -3.5 & 3.5 \\
Industry & 7.7 & 12.8 & 10.3 & 9.8 & -2.6 & 3.0 \\
Services & 7.7 & 17.9 & 5.7 & 14.9 & 2.0 & 3.0 \\
Company size & & & & & & \\
Small & 12.7 & 16.2 & 7.3 & 11.4 & 5.4 & 4.8 \\
Medium & 8.1 & 16.5 & 7.0 & 11.0 & 1.1 & 5.5 \\
Large & 5.5 & 12.3 & 9.0 & 12.7 & -3.5 & -0.4 \\
Region & & & & & & \\
Belgrade & 7.7 & 20.2 & 7.0 & 16.0 & 0.7 & 4.2 \\
Vojvodina & 8.1 & 15.3 & 7.1 & 12.6 & 1.0 & 2.7 \\
Šmadija and Western & & & & & & \\
Serbia & 7.3 & 12.9 & 8.8 & 8.5 & -1.5 & 4.4 \\
& & & & & &
\end{tabular}

\footnotetext{
${ }^{1}$ The Employers Survey that was carried out in the period 2011-2013 was tailored in a way that the expansion demand could have been distinguished from the replacement demand (Bošković et al., 2010). The survey in use since 2014 onwards does not allow for this possibility.
} 


\begin{tabular}{lrrrrrrr}
\hline & \multicolumn{2}{c}{ Job creation } & \multicolumn{2}{c}{ Job destruction } & \multicolumn{2}{c}{$\begin{array}{c}\text { Net employment } \\
\text { rate }\end{array}$} \\
& $\mathbf{2 0 1 4}$ & $\mathbf{2 0 1 7}$ & $\mathbf{2 0 1 4}$ & $\mathbf{2 0 1 7}$ & $\mathbf{2 0 1 4}$ & $\mathbf{2 0 1 7}$ \\
\hline $\begin{array}{l}\text { Southern and Eastern } \\
\text { Serbia }\end{array}$ & 8.6 & 11.7 & 8.5 & 9.1 & 0.1 & 2.6 \\
Kosovo and Metohija & $\ldots$ & $\ldots$ & $\ldots$ & $\ldots$ & $\ldots$ & $\ldots$ \\
Total & $\mathbf{7 . 7}$ & $\mathbf{1 4 . 8}$ & $\mathbf{8 . 1}$ & $\mathbf{1 1 . 8}$ & $\mathbf{- 0 . 4}$ & $\mathbf{3 . 0}$ \\
\hline
\end{tabular}

Source: Self-calculation based on the NES Employers Survey for 2014 and 2017.

Note: Just a few companies from Kosovo and Metohija region participated in the Employers Survey. (...) stands for an unreliable estimate.

The negative influence of economic and financial crisis on employment growth was more pronounced in the Serbian labour market than in the labour markets of remaining countries of the Western Balkans. The two other countries with significant loss of jobs were Bosnia and Herzegovina and Montenegro, while, for example, the labour markets in Albania and Macedonia were more resilient to the prolonged effects of the crisis. Since 2012 the trends have changed, and the Serbian labour market has led the regional employment growth with the 2016-2012 change in net job creation that exceeded 15\% (Oruč and Bartlett, 2018). These findings are in line with the previous results of the NES Employers Survey for Serbia.

The demand for occupations has not been changed that much in 2017 compared to 2014 (Figure 1). The largest occupational needs are identified in the occupational class that encompasses services, sales, craft and related trade workers - the employers report that the expected number of new jobs for respective occupations will increase to $37.2 \%$ in 2017. This group primarily includes occupations acquired in secondary general and vocational schools. Professionals and plant and machine operators, and assemblers are the second and third ranked occupational classes among most needed by the private sector companies. The private sector demand for every of these occupational classes exceeds 5000 individuals per year. ${ }^{2}$ However, the demand for individual occupations varies across years. Elementary occupations are also reported as needed in the labour market. The demand for low-skilled workers was estimated at nearly $14.0 \%$ in 2017.

\footnotetext{
${ }^{2}$ The answers in the NES Employers Survey are not weighted. However, the sample of the companies with ten and more employees is representative at a level of economic sector, company size and region.
} 
When low and intermediate demand is observed, the differences in the employers' expectations were not pronounced between the years 2014 and 2017. Managers and skilled agricultural, forestry and fishery workers were identified as occupations which demand would not exceed 1000 new jobs per year. ${ }^{3}$ Intermediate level of demand was expected for high-skilled technicians and associate professionals, as well as for medium-skilled clerical support workers.

Figure1: Companies expectations about new job openings by occupation (in \%)

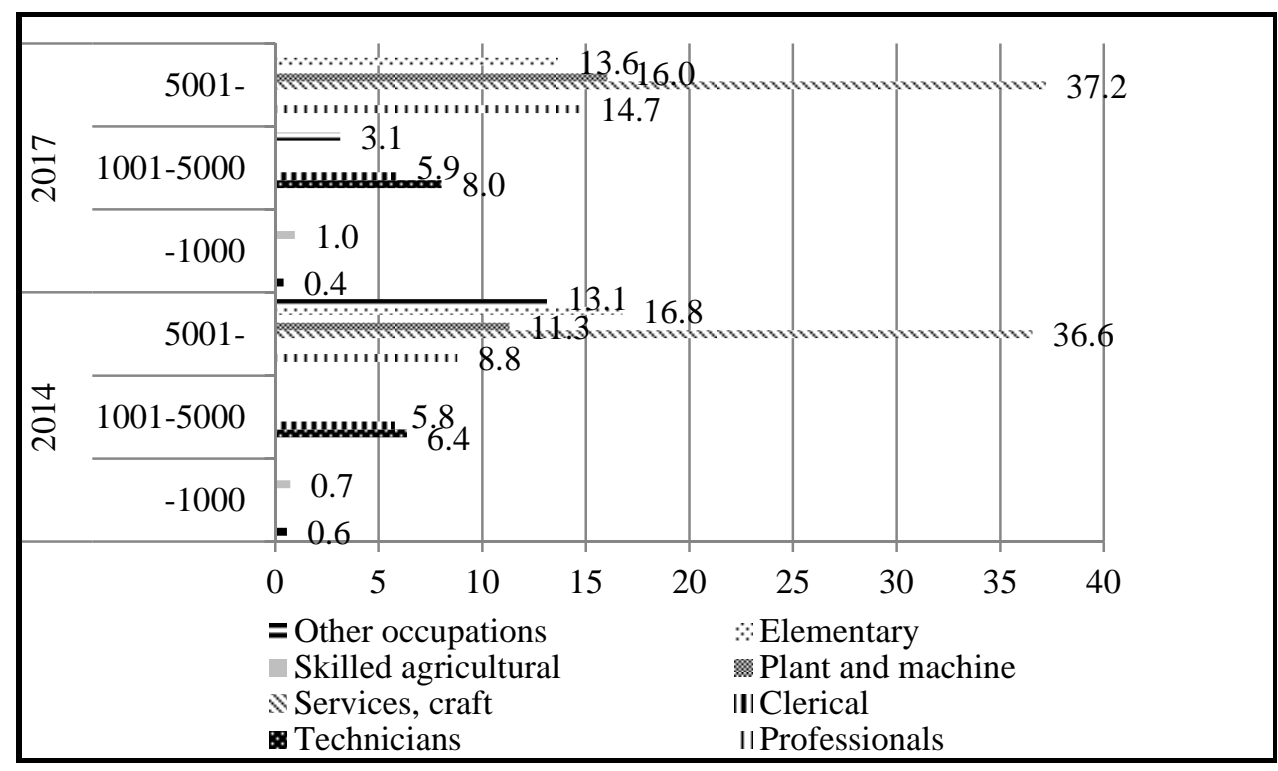

Source: Self-calculation based on the NES Employers Survey for 2014 and 2017.

Note: the intervals \{[-1000]; [1001-5000]; [5001-]\} stand for up to 1000, between 1000 and 5000, and more than 5000 employees.

Given the poll of the unemployed and new graduates who enter the labour market every year, it is obvious that educational and training institutions should more closely tie their enrolment and other policies with the labour market needs. Studying the supply and demand of higher education graduates in the Serbian labour market, Uvalić and Bartlett (2016) find that the educational system produces more graduates than the labour market needs. The main reason lies in the fact that the dynamics of new jobs creation is slow when compared with the supply of graduates generated by

\footnotetext{
${ }^{3}$ See the previous footnote.
} 
the educational system. Based on the projections for the period 2015-2018, the authors identified the shortage of graduates of only two fields of studies, including social sciences, journalism and information, and natural sciences, mathematics and statistics. The largest surplus of potential job candidates was identified in the fields of engineering ${ }^{4}$, manufacturing and construction, and business, administration and law. ${ }^{5}$ These results partly match the findings based on the NES Employers Survey that indicates that occupations related to the occupational classes professionals and technicians compose more than one-fifth of the private sector companies' annual needs for workers.

The private sector employers are more concerned about wider competencies and abilities of the potential job candidates than about their professional and transferable knowledge and skills. ${ }^{6}$ For example, in the 2017 Employers Survey wider competencies and personal characteristics were reported as most desirable exceeding the transferable knowledge and skills by almost double (NES, 2018). However, in 2014 transferable knowledge and skills were more frequently reported by the employers exceeding the requirements for specific professional knowledge and skills by more than twice (NES, 2015).

\footnotetext{
${ }^{4}$ Probably not all studies in the fields of engineering and information and communication technologies contribute to the surplus supply of graduates. For example, there are ICTbased occupations where identified demand significantly exceeds the supply of graduates. The higher education institutions in Serbia changed their enrolment policies, based on labour market requirements (Government of the Republic of Serbia, 2018a).

${ }^{5}$ Similarly, the regional labour market of the Western Balkans may expect a significant shortage of the supply of individuals who graduated in the field of natural sciences, mathematics and statistics, while, opposite the huge surplus can be expected in the supply of graduates who finished their studies in the field of business, administration and law (Bartlett et al., 2016).

${ }^{6}$ The taxonomy of skills used in the NES Employers Survey differs, for example, from the one used in the Survey of Adult Skills (OECD, 2016). The 'employability' and 'personal' skills can be matched with the key competencies in the following way: 'cognitive competencies' include literacy, problem solving, learning, numeracy, 'intra and interpersonal competencies' are equal to collaboration with others, learning stile, and organization and planning propensity, while 'technological competencies' include ICT use in the workplace and everyday life (OECD, 2016, p. 98). This approach identifies the most important life and work skills that are signalled by the employers as well.
} 
Table 4: Most frequently required skills and competencies ranked by the employers

\section{Competencies and skills}

Professional knowledge and skills

Technical and technological

Social and humanistic

Artistic

Medical

Transferable knowledge and skills

ICT

Different types of permits

Foreign languages

Safety and protection at work

Wider competencies and personal characteristics

Propensity to work with things/products

Accuracy and precision

Preference to the fast pace

Communication
Rank

2014
2017

Source: Self-calculation based on the NES Employers Survey for 2014 and 2017.

Changes in prioritizing skills of future employees are part of the global tendencies (Cedefop, 2015). Given the rising employment in the services sector, besides some occupation-specific skills needed to boost efficiency in the workplace, it is desirable for employees to master a wider range of competencies and abilities. Occupation-specific skills, ICT-based skills, skills which usage require some type of permits and certificates, communication skills and abilities are the skills almost every employer expects from their employees. Table 4 presents the four best ranked groups of skills in terms of their frequency in the employers' requirements. In the first group of occupation-specific skills, almost no change was recorded in 2017. In the group of transferable skills possession of permits and certificates was more important than ICT-based skills, while among wider competencies communication skills were best ranked followed by accuracy and precision in performing tasks. 


\section{Recruitment of Employees and Training Intentions}

The way companies recruit new staff is likely to differ depending on the size class, potential cooperation with the educational institutions and recruitment agencies, geographical location, etc. How the companies are successful in finding adequate staff can be estimated by the number of job openings, reported difficulties (such as occupational and skills deficits and mismatches) and the average time needed to fill positions.

Table 5: Reported difficulties to find workers with required skills by sector, size and region (in \%)

\begin{tabular}{lrr}
\hline & $\mathbf{2 0 1 4}$ & $\mathbf{2 0 1 7}$ \\
\hline Economic sector & & \\
Agriculture & 2.8 & 2.8 \\
Industry & 59.6 & 59.8 \\
Services & 37.6 & 37.4 \\
Company size & & \\
Small & 59.9 & 71.0 \\
Medium & 28.2 & 21.8 \\
Large & 11.9 & 7.2 \\
Region & & \\
Belgrade & 16.4 & 13.4 \\
Vojvodina & 26.5 & 37.6 \\
Šumadija and Western Serbia & 35.9 & 33.1 \\
Southern and Eastern Serbia & 21.2 & 15.9 \\
Kosovo and Metohija & 0.0 & 0.1 \\
Total & $\mathbf{1 0 0 . 0}$ & $\mathbf{1 0 0 . 0}$ \\
\hline Source Self-calcion
\end{tabular}

Source: Self-calculation based on the NES Employers Survey for 2014 and 2017.

More than $29 \%$ of the companies were found to have difficulty filling job vacancies in 2017, and the number of these companies has increased since 2014. Table 5 shows that difficulties to find workers with the required skills are mainly reported by the companies operating in the sector of industry, employing up to 50 workers, as well as geographically located in the regions of Vojvodina and Šumadija and Western Serbia. No changes were registered depending on the economic sector in 2017; however, it seems that small-sized companies have more difficulties with recruitment of new employees than the medium- and large-sized ones. Also, the number of 
companies with rising difficulties has been identified in Vojvodina, while in all other regions the opposite trend was registered. Additional analysis would probably reveal that these difficulties may result from sector specificity of the companies within this region.

Table 6: Reasons why job vacancies are not filled by occupation (in \%)

\begin{tabular}{|c|c|c|c|c|c|c|c|}
\hline Occupational group & 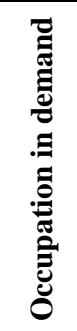 & 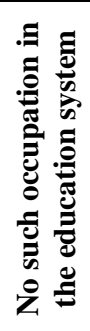 & 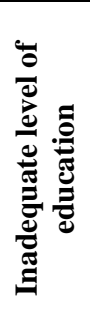 & 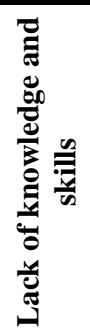 & 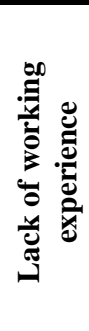 & 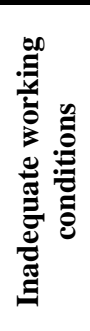 & 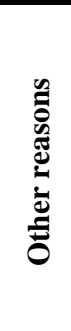 \\
\hline Managers & 0.0 & 0.0 & 0.0 & 0.4 & 0.4 & 0.0 & 0.0 \\
\hline Professionals & 22.0 & 3.7 & 17.4 & 16.2 & 20.6 & 16.1 & 11.1 \\
\hline Technicians and associate professionals & 4.5 & 6.2 & 3.0 & 7.6 & 7.2 & 6.5 & 8.2 \\
\hline Clerical support workers & 0.8 & 1.2 & 0.8 & 4.4 & 4.6 & 3.2 & 4.0 \\
\hline Services, sales, craft and related trade workers & 56.5 & 68.9 & 66.7 & 57.0 & 52.0 & 45.2 & 46.8 \\
\hline Skilled agricultural, forestry and fishery workers & 0.0 & 0.0 & 0.0 & 0.4 & 0.1 & 1.6 & 0.0 \\
\hline Plant and machine operators, and assemblers & 14.0 & 18.0 & 9.8 & 11.6 & 13.5 & 16.1 & 12.5 \\
\hline Elementary occupations & 2.1 & 1.2 & 2.3 & 2.2 & 1.2 & 9.7 & 16.7 \\
\hline Other occupations & 0.2 & 0.6 & 0.0 & 0.2 & 0.3 & 1.6 & 0.7 \\
\hline
\end{tabular}

Source: Self-calculation based on the NES Employers Survey for 2017.

As Table 6 depicts, most difficulties filling job vacancies are related to three groups of occupations, including high-skilled professionals, mediumskilled services and related workers, as well as skilled plant and machine operators and assemblers. For the first group, most difficulties appear due to excess demand and lack of previous work experience of potential job candidates. An inadequate supply of job applicants for the positions that would be filled by services, sales, craft and related trade workers most likely appear due to such educational profile does not exist in the system or because job applicants do not have required level of education. Given that this occupational group is very heterogeneous the companies experienced many difficulties to find workers of required qualifications and skills. Problems to fill job vacancies with plant and machine operators and assemblers are mainly related to the situation that a particular job needs a 
worker of specific profile usually not recognized by the educational and training system or because job candidates are not satisfied with offered working conditions.

These findings indicate that the companies are not always ready to invest in training of (future) employees to prepare them for jobs. There are various reasons for this. This is mostly due to lack of finance, time or staff available for in-company coaching, or because some employers are of the opinion that well-trained workers have more opportunities as, for example, bargaining for better working conditions or higher wages that could be offered by other companies (Ognjenović, 2015; Semenčenko et al., 2016).

According to findings of the NES Employers Survey, the employers are able to recognize the training needs at the level of the company. However, the missing part of this survey is the assessment of needs of employees to complete the training needs analysis and provide some valuable inputs for the educational and training institutions. Also, the information on how the skills acquired during the process of education and training are used in the companies is missing. Intentions of the companies to provide specialized training to their employees are usually related to the needs arising from the obligation that an employee must possess certain permits and certificates in order to perform a job, or it is some type of training for medium-skilled employees. The improvement of transferable knowledge and skills is achieved most often through training in foreign languages and ICT, while wider competencies and personal characteristics imply improved skills in communication, abilities and engagement in the workplace.

The companies in Serbia allocate scarce resources to training. For example, Ognjenović (2015) found the share of investments allocated to on-the-job training as insignificant, while Semenčenko et al. (2016) concluded that only $12 \%$ of small- and medium-sized companies allocate a certain part of the annual budget to some training of employees. In the European environment, on the other hand, about $20 \%$ of the companies provide on-the-job training to all employees, and only $13.0 \%$ of them do not provide training at all (Eurofound, 2015).

\section{Conclusion}

This paper provides an analysis of the private sector companies' training intentions and an assessment of the occupational and skills needs in the Serbian labour market, using the NES Employers Survey data as well as 
data from other relevant sources. The results pointed out that since 2012 the Serbian labour market has exhibited the highest net employment rates among the Western Balkan countries. A rising demand was primarily revealed in the occupational classes encompassing services, craft and related trade workers, followed by professionals and skilled blue colour workers ranked as the second and third ones among those the employers expect to employ within a one-year projection horizon. Likewise, a significant deficit was identified in the group of occupation-specific skills and wider competencies. Somewhat less than one-third of the companies have difficulties to fill job positions and this situation deteriorated when compared with the reference year. Even though the companies allocate scarce resources to training, their training intentions signalled to the permanent need for the enhancement of present and future employees' skills. This leads to the conclusion that training propensity depends on a number of organizational and other factors.

There are several more issues that should be addressed in future research. For example, future research should be focused on what new occupations appeared in the period between two researches (not recognized by education and training providers), but also what occupations are likely to become obsolete. Then, how the employers are satisfied with the skills of first job seekers, and how their skills are used in the companies. How the taxonomy of skills can be reformulated to make it more relevant for the requirements of modern economies. Another issue is how to increase the responsiveness of educational and training institutions, employers and employees when substantial skills deficits are identified.

Also, the shortcomings of the available data sources revealed in this paper need to be carefully analyzed before considering the possibility of amending the existing methodology for assessing skills needs.

\section{Acknowledgements}

This paper is a result of research projects under the code 179015 (Challenges and Prospects of Structural Changes in Serbia: Strategic Directions for Economic Development and Harmonization with EU Requirements) and 47009 (European Integrations and Social and Economic Changes in Serbian Economy on the Way to the EU) financed by the Ministry of Education, Science and Technological Development of the Republic of Serbia. 


\section{References}

[1] Acemoglu, Daron, and Jorn-Steffen Pischke. 1998. "Why do firms train? Theory and evidence. "The Quarterly Journal of Economics, 113(1): 79-119. https://doi.org/10.1162/003355398555531

[2] Bartlett, Will. 2013. "Structural unemployment in the Western Balkans: challenges for skills anticipation and matching policies." European Planning Studies, 21(6): 890-908. http://dx.doi.org/10.1080/09654313.2012.722933

[3] Bartlett, Will, Uvalić, Milica, Durazzi, Niccolo, Monastiriotis, Vassilis, and Tanguy Sene. 2016. From University to Employment: Higher Education Provision and Labour Market Needs in the Western Balkans Synthesis Report. Luxembourg: Publications Office of the European Union. https://ec.europa.eu/education/sites/education/files/2016-higher-educationlabour-market-balkans_en.pdf (accessed May 15, 2018).

[4] Bejaković, Predrag, and Željko Mrnjavac. 2014. "Skills mismatches and anticipation of the future labour market need: case of Croatia." Zagreb International Review of Economics and Business, 17(1): 47-68.

[5] Bošković, Olgica, Zaman, Constantin, and Kosovka Ognjenović. 2010. Methodology for Analysing the Labour Market and Forecasting Labour Market Needs in the Republic of Serbia. Belgrade, December 2010. (European Commission: Project no. EuropeAid/128079/C/SER/RS.)

[6] Brixiova, Zuzana, Li, Wenli, and Tarik Yousef. 2009. "Skill shortages and labor market outcomes in Central Europe." Economic Systems, 33(1): 45-59. https://doi.org/10.1016/j.ecosys.2008.07.002

[7] Commander, Simon, and Janos Kollo. 2008. "The changing demand for skills." Economics of Transition, 16(2): 199-221. https://doi.org/10.1111/j.1468-0351.2008.00303.x

[8] Ellis, Simon P. 2003. "Anticipating employers' skills needs: the case for intervention." International Journal of Manpower, 24(1): 83-96. https://doi.org/10.1108/01437720310464981

[9] European Centre for the Development of Vocational Training [Cedefop]. 2015. Skill Shortages and Gaps in European Enterprises. Luxembourg: Publications Office of the European Union.

[10] Eurofound. 2015. Third European Company Survey - Overview report: Workplace practices - Patterns, performance and well-being. Luxembourg: Publications Office of the European Union.

[11] Government of the Republic of Serbia. 2018a. Economic Reforms Program for the Period 2018-2020. http://www.mfin.gov.rs/UserFiles/File/strategije/2018/ERP\%2020182020\%20SRB\%20FINAL.pdf (accessed May 15, 2018).

[12] Government of the Republic of Serbia. 2018b. Fiscal Strategy for 2018 with

Projections for the

Period

2019-2020. 
http://www.mfin.gov.rs/UserFiles/File/strategije/2018/Fiskalna\%20strategija \%202018.pdf (accessed May 15, 2018).

[13] National Employment Service [NES]. 2018. Employers Survey for 2017. Belgrade: NES.

[14] National Employment Service [NES]. 2015. Employers Survey for 2014. Belgrade: NES.

[15] Neirotti, Paolo, and Emilio Paolucci. 2013. "Why do firms train? Empirical evidence on the relationship between training and technological and organizational change." International Journal of Training and Development, 17(2): 93-115. https://doi.org/10.1111/ijtd.12003

[16] OECD. 2016. The Survey of Adult Skills: Reader's Companion, Second Edition, OECD Skills Studies. Paris: OECD Publishing.

[17] Ognjenović, Kosovka. 2015. "On-the-job training and human resource management: how to improve competitive advantage of an organization?" Organizacija, 48 (1): 57-70. http://dx.doi.org/10.1515/orga-2015-0005

[18] Oruč, Nermin, and Will Bartlett. 2018. Labour Markets in the Western Balkans: Performance, Causes and Policy Options. Sarajevo: Regional Cooperation Council. https://www.rcc.int/pubs/58/labour-markets-in-thewestern-balkans-performance-causes-and-policy-options (accessed May 15, 2018).

[19] Semenčenko, Dušica, Popović-Pantić, Sanja, and Lazar Živković. 2016. "Training as the indicator of female entrepreneurship development, and training needs analysis." Journal of Women's Entrepreneurship and Education, 1-2: 18-36.

[20] Statistical Office of the Republic of Serbia [SORS]. 2018. Labour Force Survey for 2017. Bulletin No. 634. Belgrade: SORS.

[21] Statistical Office of the Republic of Serbia [SORS]. 2015. Labour Force Survey for 2014: Revised. Bulletin No. 599. Belgrade: SORS.

[22] Uvalić, Milica, and Will Bartlett. 2016. From University to Employment: Higher Education Provision and Labour Market Needs in Serbia. Luxembourg: Publications Office of the European Union. https://ec.europa.eu/education/sites/education/files/2016-higher-educationlabour-market-balkans_en.pdf (accessed May 15, 2018).

[23] World Bank/WIIW. 2018. Western Balkans Labor Market Trends 2018. Vienna: SEE Jobs Gateway Research Study, March, 2018. https://www.seejobsgateway.net/sites/job_gateway/files/Western\%20Balkan s\%20Labor\%20Market\%20Trends\%202018.pdf (accessed May 15, 2018)

Article history: $\quad$ Received: 17 May, 2018

Accepted: 18 June, 2018 